\title{
Literacy and the workplace revolution: a social view of literate work practices in Industry 4.0
}

\author{
Lesley Farrell*, Trent Newman, and Chris Corbel
}

\author{
All of the University of Melbourne, Graduate School of Education, Australia
}

\begin{abstract}
The Fourth Industrial Revolution is widely acknowledged as a digital technological revolution building on the convergence of Robotics, the Internet of Things, and the Internet of Services. What is less often acknowledged is that it is also a revolution in the social practice of work. Literacy is a core social technology of work and it is changing as rapidly and radically as the digital technologies that are reshaping work, workers and working. This article is concerned with this new generation of workplace literacy practices as they shape, and are shaped by, the Fourth Industrial Revolution - what we call Literacy 4.0. We explore two related fields of inquiry. The first is research related to the impact of technology on work practice, work organization, and employment in a period sometimes called the Fourth Industrial Revolution. The second is research about literacy, specifically workplace literacy. In this paper we argue that it is necessary to take account of each of these fields of inquiry if we are to better understand how the next generation of workplace literacy practices is emerging and serving to make, maintain and repair relationships between people, organizations and technologies in global/local networks of production.
\end{abstract}

Keywords: literacy; industrial revolution; Industry 4.0; automation; workers; workplace communication; workforce education; assessment

\section{Introduction}

Artificial intelligence is transforming work - reshaping not just the production process but the ways that products and services are imagined, developed, produced, distributed and received. The defining feature of this transformation is convergence the replacement of independent work nodes with integrated, interconnected, cyberphysical systems. Within these systems, machines are doing more and more of the routine work that people used to do. There is some new work for people, but that work is almost always novel or innovative, often precarious and almost always requires technology-mediated literacy skills and practices (Corbel, Farrell and Newman, forthcoming). In order to better understand the implications of these transformations in work for education and training, we need to better understand work-related literacy practice in hyper-connected workplaces/spaces.

In policy discussion and debate, the argument is commonly advanced that the literacy skills of the contemporary workforce are not keeping up with the literacy demands of the emerging workplace. The Australian Industry Group, for instance,

\footnotetext{
* Corresponding author's email: Lesley.farrell@unimelb.edu.au
} 
reports that $93 \%$ of manufacturing employers identify low levels of workforce literacy and numeracy as problems for their businesses (AiG, 2018). The Productivity Commission (2018; see also Shomos and Forbes, 2014) is concerned that nearly half of all Australian adults do not meet the Level 3 benchmarks of the OECD Program for the International Assessment of Adult Competencies (PIAAC). They are not alone in perceiving this issue to be urgent. Concern about the relationship between the literacy skills of individuals and of global workforces, the productivity of global companies, and the success of national economies as they engage with emerging cyber physical systems is shared by educators, governments and businesses. A key issue, however, is that we do not all understand the transformations in work in the same way.

Before we explore this complex terrain, we need to establish some clarity around what we mean by the terms we use to define and populate it. When we talk about literacy we are talking about the practice of reading, writing, listening and speaking about text. This is, of course, more ambiguous than it might first appear to be. As we move through our discussion about the various transformations of work, it will be evident that what constitutes a text, and which technologies are recruited to the tasks of reading, writing, listening and speaking about texts in work contexts, change almost beyond recognition from the First Industrial Revolution to the Fourth. While we value the flexibility of using the term literacy to cover, and, indeed, illuminate, all these iterations, our use of the term is none the less firmly tethered to the idea of a specific text. We do not use the term literacy as a proxy for knowledge in the sense of 'health literacy' or 'financial literacy'. Literacy is, of course, a highly contested field and the research literature which progresses these debates is not consistent in its use of this definition. The definition we are using aligns with a social view of literacy. An alternative, and often dominant perspective views literacy as a psychological skill accruing to an individual. Viewing literacy as a social practice versus viewing it as a skill (which an individual manifestly does, or does not, possess) has far reaching implications for how we teach, assess and promote literacy. We argue that it is only when we view literacy as a social practice that the distinctive literacy demands of Industry 4.0 become visible and the shortcomings of contemporary assessment regimes in relation to the contemporary workforce become evident.

In the public debate, when we think about industrial revolutions, we generally have in mind significant observable, and generally measurable, changes to work practice, work organization and work productivity. In contemporary times, we have in mind, perhaps, the impact on the trucking industry of driverless cars, or the YouTube videos produced by Amazon of their 'smart factories' with robots silently and efficiently fetching merchandise from vast rows of shelves, replacing the routine work of human blue-collar workers. It is not surprising, then, that in the context of these debates, when the focus moves to declining standards of literacy, it is these dimensions of the Fourth Industrial Revolution (often referred to as 'Industry 4.0' or '4IR') that are foregrounded and associated with what seem to be observable, and measurable, literacy 'skills'.

In this paper, we approach the issue of contemporary workplace literacy from a different perspective. We start from the position that industrial revolutions are also social revolutions and that these social revolutions are associated with fundamental changes to what count as working knowledges, working identities and working relationships. Working knowledges, identities and relationships are mediated and produced by the new literacy practices associated with new forms of work. Our aim is to consider the challenges that the processes of automation associated with artificial 
intelligence present to our understanding of what constitute working literacies as we enter and begin to navigate Industry 4.0.

Our discussion focusses on the roles that literacy plays in defining and connecting working knowledge, working identities and working relationships. We use the shorthand 'Literacy 4.0' to refer to the literacy practices generated and demanded by the forms of automation associated with Industry 4.0. While it is certainly the case that new forms of literacy change the ways that working knowledges and working identities are understood and produced, we argue that the distinctive demand that Industry 4.0 makes on literacy practice is the unrelenting attention that needs to be given to establishing, maintaining and repairing relationships. These relationships between people (often separated by geographical and temporal distance), and also between people and technologies - underpin the technological convergence that characterizes cyber-physical systems.

A distinguishing feature of Literacy 4.0 compared with previous iterations of workplace literacy is, therefore, the increased focus on the establishment, maintenance and repair of working relationships between people, technologies, organizations and the elements of globally distributed value chains. The increased focus on the literate practices associated with making and maintaining connections arises directly from the defining feature of the Fourth Industrial Revolution: technological convergence. The workplace of the Fourth Industrial Revolution is not a 'place' at all but a network of spaces (Farrell, 2009, 2015), converged systems of human workers, smart devices, data collection and analysis applications, cloud platform architecture, and, yes, robots.

When we refer to the Fourth Industrial Revolution we are focussing on the effects of this convergence. Specifically, we are focussing on technologies associated with robotics, the Internet of Things and the Internet of Services. These technologies can, and to some extent already do, operate as integrated networks. The convergence of already sophisticated digital technologies provokes both deep and broad change at an exponential pace and on an unprecedented scale. The impact extends beyond what we have previously understood to be distinct production processes to create and transform entire, globally distributed, networks of production.

When we refer to Artificial Intelligence (AI) we are referring to the broad field of machine learning and we include any device that gathers sensory data and acts on it to maximize its chance of successfully achieving its goals. Within this broad field we sometimes refer specifically to robotics - referring particularly to machines that are designed to replicate human actions. The Internet of Things and the Internet of Services are terms which refer specifically to digital connectivity which does not rely, or relies minimally, on human intervention. We use the term the Internet of Things to focus on co-ordinating networks of computing devices, machines, objects, people and animals through which data is transferred without explicit human intervention. We use the term the Internet of Services to focus on the co-ordinating networks of service infrastructure provided through the internet to establish and maintain business software applications. By way of illustration, the global company Otis makes people moving equipment including elevators and lifts. It has utilised the Internet of Things and the Internet of Services to create a:

new, connected digital ecosystem, [where] information is gathered directly from elevators and escalators via smart sensor technology. Data is then sent to the cloud where it's aggregated and analyzed, and delivered to customers and Otis' dedicated service teams, all in real-time. (Otis, 2018) 
Otis workers are part of this new digital ecosystem, and their work has changed fundamentally:

It's about putting the latest technology and predictive equipment insights in the hands of our service professionals to enhance proactive service and strengthen our customer relationships. (Otis 2018)

To put this another way, elevator repair workers, who used to fix a problem when it occurred in the physical world, are now responsible for making, maintaining and repairing relationships between the technological, the physical and the human elements of this dynamic ecosystem.

In short, the Fourth Industrial Revolution involves a fundamental shift toward hyper-connected work, and away from standardisation (now substantially and increasingly managed by machines) towards customisation (the distinctive contribution of humans). These shifts rely on new and emerging workplace literacy practices. In a hyperconnected, customised work context, where routine relationships are taken care of unobtrusively by machines, the 'points of vulnerability' are the unpredictable novel relationships which create the dynamic global web of production. These relationships are the constantly evolving global web of production on which 4IR relies. These shifts are not, however, reflected in existing literacy testing and assessment regimes which have their paradigmatic origins in the production of citizen workers who will undertake standardised forms of work. We begin our discussion by considering the historic role of literacy in previous industrial transformations, move to a discussion of technology and the transformation of work, then to a discussion of the relationship between literacy and technologies in the current era. We conclude with a discussion of the implications for literacy education in a context where literacy education appears to be presented as an answer to the most important social and economic questions that Industry 4.0 presents.

\section{Literacy and the transformation of work}

Literacy has a significant, but often complex and contradictory, association with industrial revolutions. As we grapple with contemporary claims about the economic consequences of apparently declining literacy rates it is instructive to remember that it was only relatively recently, during the period between the mid eighteenth century and the mid nineteenth century, that the First Industrial Revolution took hold in Europe. It was in the context of that first major revolution in work that, in the words of James Donald (1983), 'illiteracy became a problem (and literacy stopped being one)'.

Of course, literacy practice has been associated with forms of work since well before the First Industrial Revolution. Generally speaking, however, the reading and writing associated with work before the First Industrial Revolution was both transactional and marginal. It was transactional in the sense that it was largely concerned with record keeping (Brandt, 2014). Even the Romans relied on writing to keep track of the business activities of their far-flung empire (Kelly, 1996). It was marginal in the sense that the formal need for literacy was confined to people whose job it was to keep records. Workplaces needed some people who could read and write, but not many. In this sense literacy was a workplace skill, but it was not viewed as a particularly demanding one. It was rarely associated with highly prized trade and craft knowledge. Work was understood as physical labour (often, though certainly not 
always, highly skilled physical labour) and the products of that labour were material goods - wheat and coal, fabric, shoes, etc. The working knowledge that employers sought and valued was practical know-how animated by physical strength and dexterity. Working identities like 'apprentice' or, later, 'master craftsman', were well established and widely recognised. These identities were performed and acknowledged at local sites and regulated and protected through local trade associations and craft guilds.

The steam-powered technologies of the First Industrial Revolution began the move to the textualisation of working knowledge, transforming the social practice of work. The relationship between literacy, industrialization and economic productivity became both opaque and contentious during this era. Literacy was tied up not only with new forms of work organization and associated routine work practices and operational processes, but also with the potentially more revolutionary recalibration of what counted as working knowledge, working identities and working relationships.

It was during the First Industrial Revolution that the prospect of mass literacy became a particularly challenging conundrum for national governments. It seemed to present, at the same time, both a daunting political problem and a seductive economic solution. The political problem was the association of literacy for the masses with political ferment culminating in the revolutions of France and the United States. Even without the benefit of mass schooling, the widespread adoption of the printing press and the availability of informal networks like coffee houses meant that political tracts were being distributed, read, and widely discussed (A. Ellis, 1956; M. Ellis, 2004, 2008; Peter and Farrell, 2013). The governing classes in Britain feared that widespread literacy for the working classes (providing access to Thomas Paine's 'The Rights of Man') would inevitably lead to a challenge to the existing political order, if not outright revolution. It was thus not a straightforward matter to confine literacy practice to the procedural uses of literacy that mechanizing workplaces required.

The economic problem, which needed a solution, was the challenge of how to leverage the potential of industrial automation to maximize economic productivity without risking the political status quo. A literate workforce, if it was employed to read the instructions of the newly automated factories, could be understood as human capital. A literate workforce, if it read beyond the demands of the workplace, could be expected to foment revolutionary ideas of an entirely different kind. For the governing classes, the question was how to control and contain the literacy practices of the workforce so that they were focused on the routine procedural practices that enhanced the productivity and profits of their employer, but not the possibilities for their own emancipation.

It seemed possible, for a while, that mass literacy education, if it could be appropriately managed, could produce an adequately literate workforce that was nonetheless compliant, thus permitting the exploitation of the economic possibilities of industrialization without significant political risk. The version of literacy to be made available to the poor was narrow, limited to reading alone (writing was considered 'dangerous'), and was to be developed in newly imagined state-run schools (Donald, 1983, p. 35).

The electricity-powered technologies of the Second Industrial Revolution intensified the trend towards the textualisation of work. Working knowledge that had previously been learned by individuals and passed on from one individual to another began to be codified. It no longer accrued exclusively to highly expert individuals and regulated vocational and professional groups. Once working knowledge was written down it was, in theory at least, available to anyone who could read and had access to 
the text and this, in turn, had significant implications for the establishment and maintenance of working identity.

With the more recent Third Industrial Revolution, computerisation ensured that work-related literacy could no longer be considered marginal and overwhelmingly transactional. As physical labour became increasingly automated, workplaces relied on large cohorts of workers to develop literate practices to follow written instructions to the letter and to provide machines with the data that they needed to operate. A key feature of the literate practices accompanying computerization and the standardization of work practice was the standardization of literate practice (Farrell 2001, 2006a; Hull, 1993, 1997; Quarshie Smith, 2012).

With each successive industrial revolution, the social relations surrounding the practice of work were transformed as the relationship between literacy, industrialized forms of work, and economic productivity became complicated and contentious. This remains the case. It is difficult to separate the effects of literacy from the effects of schooling, and it is difficult to determine the extent to which new literate practices and more widespread popular literacy are a cause, or an effect, of the transformation of work (Anderson and Bowman, 1963; Bowman and Anderson, 1973; Graff, 2010; West, 1978). What does seem clear is that new literacy practices are forged in the social and political turmoil of periods of transformation, but they do not exist in isolation as discreet work-related skills with predictable and linear consequences. Literacy practices are produced by the entirety of the social conditions of which they are a part. They are also productive of those conditions.

\section{Technology and the transformation of work}

The Fourth Industrial Revolution relies on technological convergence, and technological convergence relies on relationships. These relationships are often between technologies, certainly, but they are also between people, and between people and technologies, and, crucially, they are increasingly mediated by literate practice.

The phrase 'Fourth Industrial Revolution' is becoming increasingly familiar through its pervasive use in public debate about the future of work. The most commonly cited definition situates contemporary technological transformations in the context of other technological revolutions:

The First Industrial Revolution used steam power to mechanize production. The Second used electric power to create mass production. The Third used electronics and information technology to automate production. Now a Fourth Industrial Revolution is building on the Third. It is characterized by a fusion of technologies that is blurring the lines between the physical, digital, and biological spheres. (Schwab, 2017).

Each of these technological transformations provoked changes in how work was organized and how people conducted their working lives. The first involved a shift from farms to factories, the second a shift to production lines and mass production, the third a shift to the automation of individual production processes more generally, and the fourth a shift from individual production processes to highly connected production processes incorporating both human and technological actors.

These human/technological work processes have made possible new forms of work organization that exploit the ability of technologically connected systems to 
maintain continuity in work processes while local and remote sources of human labour can be accessed to meet specific needs. A ubiquitous example is 'gig work' with its characteristically fleeting and technology-mediated contracting arrangements (de Ruyter, Brown and Burgess, 2019). Paradoxically, while technologies may allow increasingly comprehensive and durable connections between production processes and value chains, the connections of workers to the physical and organizational settings of their work are increasingly precarious and temporary.

In 1988, Zuboff, in her prescient book In the Age of the Smart Machine, distinguished between automating - the mechanization of existing work processes and procedures - and 'informating'. She introduced the term 'informating' to capture the process of translating formerly physical and material events, measurements, and processes into vast data banks of information:

As information technology is used to reproduce, extend, and improve upon the process of substituting machines for human agency, it simultaneously accomplishes something quite different. The devices that automate by translating information into action also register data about those automated activities, thus generating new streams of information. [...]Scanner devices in supermarkets automate the checkout process and simultaneously generate data that can be used for inventory control, warehousing, scheduling of deliveries, and market analysis. The same systems that make it possible to automate office transactions also create a vast overview of an organization's operations, with many levels of data coordinated and accessible for a variety of analytical efforts. (Zuboff, 1988, p. 9)

This process of 'informating' to a significant and increasing extent made redundant the physical skills and the physical exertion that had characterized what we had, until then, generally understood work to be. While technology brought the benefits of reducing both the toil and the dangers of work, the automation of physical labour was not always welcomed by the workers whose physical exertion, and whose embodied skills and knowledge, were to be replaced.

A worker in the pulp mill where Zuboff conducted her research described the experience of performing his work from a computerized control room instead of the workshop floor:

"It is hard to get used to not being out there with the process. I miss it a lot. I miss being able to see it. You can see when the pulp runs over the vat. You know what's happening." (quoted in Zuboff, 1988, p. 59)

Work, Zuboff argued, was becoming increasingly situated in a growing labyrinth of electronic texts. 'Work as reading' had become the process of reading digital texts and this skill was very different from the skills previous iterations of work demanded and nurtured. Previously, this working knowledge was sentient, embodied and animated by the knowing worker in the processes of their work practices. It was largely implicit and very rarely written down. The knowledge was also partly embedded in the specific physical context of the workplace, and it may have been shared with other workers involved in the same process at the same place. It was, in important ways, 'local' knowledge. Computerization demanded that the knowledge be removed from the physical context, be made explicit, and be written down in order to mechanize work processes. Once in the control room, the worker was reliant on the data generated by the automated production process to produce a textualised version of reality. The worker needed to be able to access this reality in order to identify problems and attempt to solve them in the physical workspace they had previously inhabited. 
With the technological innovations in work practices brought by the Third and now the Fourth Industrial Revolution, the processes involved in reading digital workplace texts are demanding, and nurturing, different workplace skills. Zubboff referred to these skills as 'intellective skills' - abstract thinking, inference drawing and procedural reasoning - all mediated by 'informating' technologies and performed through literate practice. This textualisation of work through both reading and writing (Brandt, 2014) has had profound implications for what gets recognized as working knowledge, and for the availability of inhabitable working identities - those that get relinquished, and the new ones that are created.

Thirty years on from the publication of In the Age of the Smart Machine it is again timely to consider Zuboff's question: 'What is it that distinguishes contemporary technologically-mediated work practices from previous generations of machine technology?' (1988, p. 9). Zuboff was writing before the connective potential of the internet had fully emerged and the vast information infrastructures she described were still more or less independent. Thirty years later, contemporary work practice and work organization is marked by the convergence of these previously independent information infrastructures into connected systems which join up people, technologies, organisations and procedural processes into globally connected systems of production. These emerging systems are sometimes called cyber-physical systems:

[S]mart systems that encompass computational components (i.e. hardware and software) and physical components seamlessly integrated and closely interacting to sense the changing state of the real world. (IEC, 2015; 'Factory of the Future White Paper')

Cyber physical systems bring into intimate and mutually constituent connection the two work realities which Zuboff identified- the geographical, material and temporal reality of physical workplaces and the technologically mediated reality within which that physical reality is represented and enacted. Human workers inhabit and connect these two realities.

The role of the human worker in these connected systems is undergoing a transformation. Fischer and Bergestermann (2015) observe the impact on the overall composition of the German workforce:

[T]he mid-level qualifications and skills needed for routine cognitive and manual tasks [have] become less valuable, while high-skilled employees with analytical, creative, communication and interpersonal talents can improve their material bargaining position (although not necessarily with regard to control over their own free time), and prospects for the long-term unemployed are poor, and may well deteriorate further. [..T]he time has gone when a formal degree [...] is any guarantee of decent and decently paid work - let alone a stable job. (p. 66)

As this analysis of the situation in Germany illustrates, the Fourth Industrial Revolution hybridises, reconfigures and recalibrates working identities, relationships and practices. It does so in the sense that pervasive technological convergence has the potential to, and often does, join up geographically and socioculturally remote locales in complex networked systems of production and consumption that previously would not have been possible.

It is in this sense that the Fourth Industrial Revolution is a social revolution as much as a technological revolution. It relies on the capacity of people to develop new, durable and malleable relationships and identities to create the robust relational ligatures on which connected systems, hybrid workplaces, and hybrid communities all rely. 


\section{Literacy 4.0 and its implications for education}

The Fourth Industrial Revolution is more than a technological revolution; it is also a revolution in the social practices of work. This social revolution is animated and propelled by the activities of reading, writing, listening and speaking around texts, activities that are fundamentally social in nature (Street, 1984). To understand the absolute centrality of literacy to Industry 4.0, we need to understand literacy more as a social practice, and less as a cognitive skill. While this approach is familiar in the field of literacy studies research, it is less visible in public debates about the importance of literacy in globalising workplaces.

\section{Literacy as social practice}

In the public debate, literacy is often referred to, implicitly or explicitly, as a cognitive skill accruing to an individual - an autonomous and generic skill (or suite of skills) that, once learned, can be unproblematically transferred from one context to another and applied across a range of knowledge domains and social contexts. Literacy skills, and their manifestations as 'soft skills' or $21^{\text {st }}$ century skills, are understood to be 'generic'. This understanding often underpins public discussion about national and international testing and population achievement, as evidenced in the following recent statement in the mainstream Australian media:

Australia's performance on international tests doesn't make pretty reading. [...] At the top of the performance spectrum, in 2003, 18 per cent of Australian students reached the top category of performance in reading. By 2015, that had fallen to 11 per cent of students, barely one in 10. (Jensen, 2019)

Once in possession of these 'core skills', it is implied, individuals can perform a range of sophisticated cognitive tasks:

\footnotetext{
These statistics will have a real impact on our future. The OECD and the World Bank have published numerous studies in recent years showing a country's performance on PISA tests make a more significant contribution to a country's economic performance than simply the quantity of education. (Jensen, 2019)
}

This approach, focusing as it does on the individual worker as a score in a population, does not help us to understand what is required of an individual worker in the textual production and mediation of connected systems and complex relationships that are the defining characteristics of the Fourth Industrial Revolution.

If we are to understand what people need to know and to be able to do in the contemporary workplace, we need to think about literacy differently. Specifically, we need to foreground the social dimensions of literacy and understand the ways in which it establishes and maintains the relationships which constitute highly connected workplaces.

Street $(1984,2005)$ distinguishes between the 'autonomous' model of literacy which: 'works from the assumption that literacy in itself - autonomously - will have effects on other social and cognitive practices' (2005, p. 417), and the 'ideological' model of literacy which:

starts from different premises than the autonomous model - it posits instead that literacy is a social practice, not simply a technical and neutral skill [...] It is about knowledge: the ways in which people address reading and writing are themselves rooted in conceptions of knowledge, identity, being. (2005, p. 417) 
An important implication of this approach to literacy is that we can only understand a text, or make a text, when we are aware of the social relationships of which it is a part. As Barton (2017) argues, 'we live in a textually mediated social world, where texts are part of the glue of social life' (p.38). This is because language and literacy do not only enable communication, they produce identity, produce and distribute power, and structure knowledge: 'literacy is bound up in identity, in power and how we act in the world' (p.39).

This approach to literate practice requires us to consider text and talk together and to pay attention to both the technical aspects of navigating digitized texts and also to what Lankshear, Knobel and Curran (2019) call the 'ethos' - the collaborative and distributed nature of contemporary textual practice:

The ethos dimension of new literacies refers to the intensely 'participatory', 'collaborative' and 'distributed' nature of many current literacy practices. New literacies draw on collaborative dispositions and ways of participating, supported by distributed digital networks and other Web 2.0 technologies. They emphasize participants accessing and 'developing' the distributed knowledge of communities of interests, where experts and novices work together as peers to support and advance their individual and collective ends. (p. 5)

Recognising and understanding this 'ethos dimension' to the literacies associated with contemporary technological transformations in work requires focussed attention on how working relationships are established and maintained in and through digital networks. This, in turn, requires attentiveness to the specificities of context that shape the nature of those relationships. Yet, it is most often the technical literacy 'skills' that receive the attention - traditional understandings of what counts as reading and writing, what can be easily measured and quantified, and what may be readily transferrable from one work setting to the next.

When literacy is viewed as social practice, the focus has tended to be on the local social context in which texts and utterances are produced. However, while the local certainly matters, 'more is going on locally than simply local practice' (Brandt and Clinton, 2002, p. 338). This is because it is the connections between the local and the global, established and maintained through the literate social practices of everyday work being done by everyday workers, that make global economies happen. As Farrell (2001) has put it:

the relationships that are established through these interactions are social as well as economic relationships and these relationships are the micro-processes of global economies. [...] Small local enterprises cannot operate independently, they must be intimately and routinely connected to centralised, external agencies. (pp. 59-60)

In relation to the impacts of globalisation and digitization on contemporary literate work practices, we need to better understand the intimate ways that the local and the global interact and, indeed, come to constitute one another. Brandt and Clinton propose that we interrogate the relationship between the local and the global by asking, 'What is localising and what is globalising in what is going on?' (2002, p. 337). Smith (2003) makes a similar point in arguing that we need to understand 'how everyday practices of ordinary people produce cultural meanings that sustain transnational networks and make possible enduring translocal ties' (p. 468).

Globally dispersed work teams increase the pressure on working literacies. For example, a team of software engineers with physical locations in Australia, Japan, India and the US might use Slack - an internet based instant messaging program 
popular with workplaces that have geographically diverse employees - to collaborate on the custom design and construction of a cloud platform for a client based in some fifth location. Slack immediately escalates the literacy demands on the participants. They must, to begin with, master spoken and written English (including specialised lexicon) as well as the technical knowledge of relevant IT systems. On their own, however, even specialised English language skills will not be enough. These software engineers will also need intercultural communication and conflict management skills to work with each other remotely and also to communicate about tech solutions with similarly dispersed teams of sales and marketing representatives who would manage the relationship with the client. They will also need to be able to establish and maintain a shared culture of use of Slack that will enable them to complete their relationship-building work. The training needs of such workers have changed from the transference of established literacy skills to the collaborative creation of new literacy practices. As Newman (2018) puts it with regard to the implications for education, 'the focus here shifts from 'acquisition' of discrete, bounded languages, to the [social] development of particular translingual literacies in workplace communicative cultures' (Newman, 2018, p. 198).

Workplace communication cultures are increasingly being shaped not only by the relationships built between geographically dispersed humans, but also by those built between humans and machines, devices, or software programs with artificial intelligence. As with the Otis example described earlier, existing workers are increasingly required to interact with software platforms, even though such platforms bring their own algorithms and coded agendas to the banal workplace tasks that they facilitate. These software programs are constantly adapting via machine learning across diverse contexts, so the humans must also be constantly adapting their interactions to take account of these developments.

In summary, the value of viewing the new and emerging work practices of the Fourth Industrial Revolution through the lens of literacy as a social practice lies in the ways in which such a perspective can help us to better understand the building and maintaining of the relationships on which connected, cyber-physical systems depend.

\section{Literacy as work practice: the emergence of Literacy 4.0}

When we use the shorthand term 'Literacy 4.0' we are attending to the prominence of literacy practices in shaping how work is accomplished and organized in the current period of technological transformation. The new prominence of these literacy practices generates new forms of working knowledge and makes available new forms of working identity. What is distinctive about Literacy 4.0 is that literacy practice is no longer distinguishable from work practice; literacy practice $\underline{i s}$ the work practice which creates the connectivity on which the Fourth Industrial Revolution depends.

The textualization of work that has accompanied computerisation began with the standardisation of physical work practices and then was extended to the (attempted) standardisation of cognitive processes. First, the communications technologies associated with computers accelerated the development of globally distributed value chains which relied on exhaustively documented, highly replicable, work processes. The written text became the recognised authority on work practice and working knowledge, to a significant extent displacing the local expert worker and the authority of their embodied knowledge. Computers could not cope with even slight deviations 
from the routines for which they had been programmed. Operational and quality manuals were produced which routinized work practice in order to ensure that workers engaged in work practices which fitted the relatively inflexible demands of computerisation (Farrell, 2000, 2001, 2006b). Then, as automation produced extensive and complex global networks of production, it became increasingly common to codify not just physical work practices but also the cognitive and social work practices on which automation relied.

Quality processes were designed initially to standardize work practices across global webs of production. The Quality Standard QS 9000, for instance, was a hugely influential Quality Standard associated with globally networked automotive companies and other companies in the globally distributed supply chain, during the Third Industrial Revolution. It was intended to ensure that a car assembled in South Africa or Australia was of the same reliable high quality as a car of the same brand assembled in Japan or Germany. Assembly plants, like other workplaces, were simultaneously local and global. They were local in the sense that they were situated in the geographical, social and economic contexts of a specific location but they were also unambiguously part of increasingly complex global networks of production. When things went wrong with routine production processes, as they inevitably did, it was the way these problems were solved at the local site that determined the quality of the product. When the codification of physical work practices in automated processes failed to achieve the goal of guaranteed standards of quality comprehensively, the focus shifted to the regulation of the cognitive and social interactions of workers as they solved problems at local sites.

This was the moment, late in the Third Industrial Revolution, when the social practice of non-routine work-related literacy - the use of literacy to create, maintain and repair relationships in order to collaboratively produce novel solutions to novel problems - became a recognized and highly valued workplace skill. This is not to say that people had not been calling on skilled literacy practices to solve workplace problems in the past, of course they had. It is to say that this seems to be the moment where the capacity to recruit literacy practices to this goal stopped being viewed as a personal attribute and became acknowledged instead as a skilled form of labour. As Urciuoli and La Dousa (2013) argue:

whether linguistic practices are [understood to be] social interaction or job skills depends on whether they are performed as labor. (p. 176)

The term Literacy 4.0 is intended to draw attention to this moment, where the need for routine, mundane, repetitive literacy practice is falling away (since artificial intelligence can reliably generate complex routine texts when enough examples are available) while the need for highly customized forms of literacy practice is accelerating. These are the literacy practices by which 'soft skills', 'social skills' or ' $21^{\text {st }}$ century skills' are accomplished. At the heart of these 'soft skills', or 'social skills' is innovative and sophisticated literacy practice; the ability to establish, maintain and repair textually mediated relationships in order to create the durable connections on which Industry 4.0 relies. As Heller and Duchêne (2016) have noted, 'the conditions of late capitalism extend the commodification of language in ways that make it available for work it has not had to do before' (p. 140).

Textually mediated social skills are a newly recognized, and highly prized, form of labour. This development is reflected in the labour market, which increasingly demands and rewards social skills. Deming (2017) has demonstrated that despite the 
emphasis on STEM knowledge in the public debate, given a choice between a candidate with high maths capability and low social skills, and one with low maths capability and high social skills, employers (in the US at least) will choose the candidate with low maths and high social skills. Deming notes that the strongest growth in both jobs and wages occurs when social skills are paired with technological skills and STEM knowledge, especially maths. Jobs growth is also occurring in areas requiring high social skills but low technological/STEM demands, for instance service roles in health and customer service, although wages remain low in these fields and employment is often precarious. What these areas have in common is that the emergent work practices are textually mediated and relationship oriented.

Industry 4.0 can be distinguished from previous industrial revolutions in that it relies on the commodification of innovative, non-routine literacy practice as a prized form of globalising labour. There has been a shift from an emphasis on routine, highly regulated literacy practices (associated with routine highly regulated working identities) to an emphasis on non-routine, highly innovative literacy practices (and more mutable, constantly evolving working identities), which produce and maintain the relationships between people and machines that are the foundation of the Fourth Industrial Revolution. This shift challenges many of our tacit understandings about the relationship between education and work across the life-course.

If these are the most crucial applications of literacy in the contemporary and emerging workplace, then work-related literacy education and assessment must attend to the skills, capabilities and attributes that underpin these relationship-oriented literacy practices. We should be cautious of teaching and assessing what we take to be proxies of workplace literacy rather than the actual literacy practices that people need to do their work. We can continue to teach and assess those observable and measurable literacy skills traditionally associated with routine procedural work practices, but not at the expense of the non-routine, even innovative, literacy practices on which contemporary working relationships rely. If we do so, we are in danger of failing to provide students and vocational trainees with the interactive and communicative competencies they need to engage productively with new forms of work. We also deny organizations the literate workforces they need to compete in technologically connected global markets.

There are, of course, risks in developing literacy curricula and assessment that emphasize creative connectivity and innovation. In relation to working knowledges, connectivity-oriented literacy practices encourage the sharing of existing knowledge across organizational and disciplinary boundaries, rather than its protection, and the generation of new forms of knowledge rather than the reification and replication of existing knowledge and work practice. In relation to working identities, these literacy practices encourage creative agency over routine compliance. It can be difficult (although by no means impossible) to exert control over a workforce which is granted such latitude in the literacy practices it may call upon to establish, maintain and repair the working relationships on which connected systems depend. This may, however, be a risk that governments and globally networked organisations are prepared to take. 


\section{Literacy 4.0, education and assessment}

The current period of technological transformation makes new literacy demands of global/local workforces. The literacy practices that are coming to count are no longer associated with standardizing work practices to produce identical products across a globally distributed network of production and distribution. Where routine forms of reading and writing - formerly understood as 'generic' literacy skills - are required, they are increasingly generated by artificial intelligence. This trend will only increase exponentially as data banks of routine textualised human interactions expand and the means of mining them become more sophisticated. The literacy practices that are coming to count as uniquely human contributions are the innovative, nonroutine practices that make and sustain the relational connections upon which cyberphysical systems rely. These literacy practices make, maintain and repair relationships between people, organizations and technologies in global/local networks of production. They are the social practices that leverage the convergence, and manage the abrasion, of distinct forms of specialized technical, professional, industrial and contextual knowledge by sustaining these relationships. It is these literacy practices that are increasingly being acknowledged and valued as skilled forms of labour.

In 2007, just as the Third Industrial Revolution began morphing into the Fourth, Farrell and Fenwick (2007) posed the question 'What is involved, and what is at stake, in educating a global workforce for a knowledge economy?' The answer was confronting:

Clearly for some countries, perhaps for many, this implies a complete reconfiguration, not only of vocational education and training but also of schooling, higher education and professional education. In some critical senses, all education is understood as work related education. It is difficult to overestimate the fundamental changes that such a reconfiguration implies. (p.15)

Globally, the rhetoric surrounding education as a whole - and assessment regimes in particular - has indeed become overwhelmingly focused on the preparation of a global workforce for a new world of work. However, while work is accelerating into the Fourth Industrial Revolution with breathtaking speed, education is struggling to keep pace. The acknowledged goal, at all levels of education, on the development of literacy as a fundamental work practice, reflects the acknowledged need for autonomous, creative, problem solving workers. The focus of large-scale assessment regimes, and the curriculum that is inevitably generated by them, is in direct contradiction to that goal. The likely effect, if not the aim, of these regimes is the production of standardized literacy practices to produce standardized, compliant workers. This is not surprising. There has, since the First Industrial Revolution, been a tension between the potential of literacy to create a compliant workforce and literacy's emancipatory power. As we are digitally catapulted into the Fourth Industrial Revolution, with no time left to lose, educators and policy makers need to recognize that the literacy practices that emancipate individuals and that enable truly democratic, connected, local communities, are those literacy practices that provide the ligatures of the cyber-physical systems that are coming to constitute the contemporary workspace. If people are to have meaningful employment as the Fourth Industrial Revolution progresses, then our education systems, and our assessment regimes, must pivot to reflect this new reality. 


\section{References}

AiG [Australian Industry Group]. (2018). Skilling: A national imperative [Workforce Development Needs Survey Report]. Melbourne: Australian Industry Group. Retrieved from: https://cdn.aigroup.com.au/Reports/2018/Survey_Report_WFDNeeds_Skilling_Sept2018.pdf

Barton, D. (2017). Literacy: An introduction to the ecology of written language. John Wiley \& Sons.

Anderson, C. A., \& Bowman, M. J. (1963). Concerning the role of education in development. In C. Geertz (Ed.), Old societies and new states: The quest for modernity in Asia and Africa (pp. 247279). London: Collier Macmillan.

Bowman, M. J., \& Anderson, C. A. (1973). Human capital and economic modernization in historical perspective. In Fourth International Conference of Economic History. Paris: Mouton Press.

Brandt, D. (2014). The rise of writing: Redefining mass literacy. Cambridge, MA: Cambridge University Press.

Brandt, D., \& Clinton, K. (2002). Limits of the local: Expanding perspectives on literacy as a social practice. Journal of Literacy Research, 34(3), 337-356. doi: 10.1207/s15548430j1r3403_4

Corbel, C., Farrell, L., \& Newman, T. (forthcoming). The literacy practices of the gig economy. The Literacy 4.0 Project Working Papers. Melbourne Graduate School of Education.

de Ruyter, A., Brown, M., \& Burgess, J. (2019). Gig work and the Fourth Industrial Revolution: Conceptual and regulatory challenges. Journal of International Affairs, 72(1), 37-50.

Deming, D. J. (2017). The growing importance of social skills in the labor market. The Quarterly Journal of Economics, 132(4), 1593-1640.

Donald, J. (1983). How illiteracy became a problem (and literacy stopped being one). Journal of Education, 165(1), 35-52.

Ellis, A. (1956). The penny universities: A history of the coffee-houses. London: Secker \& Warburg.

Ellis, M. (2004). The coffee-house. London: Weidenfeld \& Nicolson.

Ellis, M. (2008). An introduction to the coffee-house: A discursive model. Language \& Communication, 28(2), 156-164.

Farrell, L. (2000). Ways of doing, ways of being: Language, education and 'working' identities. Language and Education, 14(1), 18-36.

Farrell, L. (2001). The 'new word order': Workplace education and the textual practice of economic globalization. Pedagogy, Culture and Society, 9(1), 57-75. doi: 10.1080/14681360100200103

Farrell, L. (2006a). Labouring in the knowledge fields: Researching knowledge in globalising workspaces. Globalisation, Societies and Education, 4(2), 237-248.

Farrell, L. (2006b). Making knowledge common: Literacy and knowledge at work. New York: Peter Lang.

Farrell, L. (2009). Texting the future: Work, literacies, and economies. In M. Baynham, \& M. Prinsloo (Eds.), The future of literacy studies (pp. 181-198). New York: Palgrave Macmillan.

Farrell, L. (2015). Workplace literacies and the factories of the future [Professorial Lecture]. Melbourne Graduate School of Education.

Farrell, L. and Fenwick, T. (2007) Educating the Global Workforce. In L. Farrell and T. Fenwick (Eds) Educating the Global Workforce. Knowledge, Knowledge Work and Knowledge Workers. London and New York: Routledge (pp13-25).

Fischer, M., \& Bergstermann, J. (2015). Unpicking the German jobs miracle: Is Germany a labour market role model? In T. Dolphin (Ed.), Technology, globalisation and the future of work in Europe: Essays on employment in a digitised economy (pp. 63-68). London: IPPR. 
Gee, J. P., Hull, G., \& Lankshear, C. (1996). The new work order: Behind the language of the new capitalism. Sydney: Allen \& Unwin.

Graff, H. J. (2010). The literacy myth at thirty. Journal of Social History, 43(3), 635-661.

Heller, M., \& Duchêne, A. (2016). Treating language as an economic resource: Discourse, data and debate. In N. Coupland (Ed.), Sociolinguistics: Theoretical debates (pp. 139-156). Cambridge, MA: Cambridge University Press.

Hull, G. (1993). Hearing other voices: A critical assessment of popular views on literacy and work. Harvard Educational Review, 63(1), 20-49.

Hull, G. (Ed). (1997). Changing work, changing workers: Critical perspectives on language, literacy, and skills. New York: SUNY Press.

IEC [International Electrotechnical Commission]. (2015). Factory of the future (White Paper). Geneva: IEC. Retrieved from: https://www.iec.ch/whitepaper/pdf/iecWP-futurefactory-LR-en.pdf

Jensen, B. (2019). What do schools teach? It's surprising how little we know. Australian Financial Review. Retrieved from: https://www.afr.com/policy/health-and-education/what-do-schools-teachit-s-surprising-how-little-we-know-20190410-p51cwh

Kelly, C. M. (1996). Later Roman bureaucracy: Going through the files. In A. K. Bowman, \& G. Woolf (Eds.), Literacy and power in the ancient world (pp. 161-176). Cambridge University Press.

Lankshear, C., Knobel, M., \& Curran, C. (2012). Conceptualizing and researching 'new literacies'. In C. A. Chapelle (Ed.), The encyclopedia of applied linguistics. London: Blackwell. doi: $10.1002 / 9781405198431$

Newman, T. (2018). Transforming lexicon, transforming industry: University lecturers as language planners in Timor-Leste. In J. Choi, \& S. Ollerhead (Eds.), Plurilingualism in teaching and learning: Complexities across contexts (pp. 185-200). New York: Routledge.

Otis. (2018). Otis Launches 'Otis ONE' IoT Service Solution for the world's largest elevator service network [web page]. Retrieved from: https://www.otis.com/en/us/about/news-and-media/pressreleases/otis_launches_otis_one_iot_service_solution_worlds_largest_elevator_service_network.as px

Peter, S., \& Farrell, L. (2013). From learning in coffee houses to learning with open educational resources. E-Learning and Digital Media, 10(2), 174-189.

Productivity Commission. (2018). Child care, education and training. Report on Government Services, 2018. Canberra: Productivity Commission. Retrieved from: https://www.pc.gov.au/research/ongoing/report-on-government-services/2018/child-careeducation-and-training

Quarshie Smith, B. (2012). Reading and writing in the global workplace: Gender, literacy and outsourcing in Ghana. New York: Lexington Books.

Schwab, K. (2017). The Fourth Industrial Revolution. Penguin UK.

Shomos, A., \& Forbes, M. (2014). Literacy and numeracy skills and labour market outcomes in Australia, Productivity Commission Staff Working Paper, Canberra. Retrieved from: https://www.pc.gov.au/research/supporting/literacy-numeracy-skills/literacy-numeracy-skills.pdf

Smith, D. E. (2003). Making sense of what people do: A sociological perspective. Journal of Occupational Science, 10(1), 61-64.

Street, B. (1984). Literacy in theory and practice. Cambridge, MA: Cambridge University Press.

Street, B. (2005). At last: Recent applications of new literacy studies in educational contexts. Research in the Teaching of English, 39(4), 417-423. 
Urciuoli, B., \& La Dousa, C. (2013). Language management/Labor. Annual Review of Anthropology, $42,175-190$.

West, E. G. (1978). Literacy and the industrial revolution. The Economic History Review, 31(3), 369383.

Zuboff, S. (1988). In the age of the smart machine: The future of work and power. New York: Basic Books. 


\section{University Library}

\section{- M M N E R VA A gateway to Melbourne's research publications}

Minerva Access is the Institutional Repository of The University of Melbourne

Author/s:

Farrell, L;Newman, T;Corbel, C

Title:

Literacy and the workplace revolution: a social view of literate work practices in Industry 4.0

Date:

2020-05-05

Citation:

Farrell, L., Newman, T. \& Corbel, C. (2020). Literacy and the workplace revolution:

a social view of literate work practices in Industry 4.0. DISCOURSE-STUDIES

IN THE CULTURAL POLITICS OF EDUCATION, 42 (6), pp.898-912. https://

doi.org/10.1080/01596306.2020.1753016.

Persistent Link:

http://hdl.handle.net/11343/294180 